\title{
Chimbote en El zorro de arriba y el zorro de abajo de José María Arguedas: entre la sociedad urbana y la sociedad rural
}

\section{Chimbote in El zorro de arriba y el zorro de abajo by José María Arguedas: in between the Urban and Rural Society}

\author{
María José Barros \\ Pontificia Universidad Católica de Chile, Chile \\ mjbarrol@uc.cl
}

Resumen - El artículo se centra en la representación de Chimbote en la novela El zorro de arriba y el zorro de abajo del escritor peruano José María Arguedas, donde la ciudad se configura como un espacio en tensión y heterogéneo, en el cual coexisten expresiones de la sociedad urbana y la sociedad rural. Tras dicha representación de la ciudad, nos adentramos en la visión particular de Arguedas respecto a la modernidad, la modernización y la cultura.

Palabras clave: Ciudad, Sociedad urbana, Sociedad rural, Heterogeneidad, Modernidad

Abstract - The article focuses on the representation of Chimbote in the novel El zorro de arriba y el zorro de abajo by Peruvian writer José María Arguedas, who portrays the city as a heterogeneous space in tension where expressions of the urban and rural societies coexist. Additionally, an in-depth analysis of Arguedas' particular vision of modernity, modernization and culture is provided.

Keywords: City, Urban Society, Rural Society, Heterogeneity, Modernity 


\section{ADVENIMIENTO DE UNA NUEVA REALIDAD: LA CIUDAD MASIFICADA}

Hacia mediados del siglo xx, una nueva realidad citadina se asentó en el Perú, una manifestación local de un fenómeno que abarcó, de forma matizada y desigual, a toda Latinoamérica. De acuerdo a lo señalado por José Luis Romero, durante la crisis mundial de 1930, las ciudades latinoamericanas comenzaron a masificarse. Grandes oleadas migratorias (ante todo rurales, pero también provenientes de pequeñas y medianas ciudades en decadencia) se asentaron en determinados centros urbanos, lo que produjo una explosión sociodemográfica que devino en una explosión urbana. Importantes ciudades se transformaron en metrópolis, al mismo tiempo, urbes de menor envergadura, producto de un desarrollo compulsivo, llegaron rápidamente a ser grandes ciudades. La ciudad se convirtió, entonces, en un nuevo horizonte de expectativas y posibilidades para miles de latinoamericanos, que vieron en la urbe la promesa feliz de aquella modernización que ciertos grupos minoritarios ya habían comenzado a experimentar.

Es en este contexto en el cual Chimbote, una aldea de pescadores de Perú, se vio transformada hacia mediados de la década de los 50 en una gran ciudad industrial. Productora, principalmente, de harina y aceite de pescado, llegó a ser el primer puerto pesquero del mundo durante algún tiempo. Esta nueva realidad del acontecer peruano llamó la atención del escritor y antropólogo José María Arguedas, llevándolo a escribir sobre ella. Su nuevo proyecto literario se concretó en la novela El zorro de arriba y el zorro de abajo, publicada póstumamente en 1971. Por algunas cartas del escritor ${ }^{1}$, nos enteramos de que su primera intención era escribir sobre Supe, puerto cercano a Lima, donde veraneó durante varios años. Así lo relata en una misiva al editor Carlos Barral: «Fui testigo de la transformación del puerto y de sus gentes. De cómo esta silenciosa y paradisíaca caleta se convirtió en una especie de urbe entremezclada de negros, cholos, indios monolingües quechuas, chinos e injertos, prostitutas, ladrones y de empresarios sin entrañas» (276). Pero luego de varias visitas a la ciudad de Chimbote, donde recopiló múltiples datos etnográficos, decidió centrar su novela en este puerto industrial mayor, dejando atrás y de forma definitiva el escenario de los Andes, el mundo de arriba o la sierra.

El escenario de la escritura se trasladó a la costa por una razón: la nueva ciudad industrial reunía, en su seno, a la totalidad del universo peruano, haciendo eco de la complejidad cultural y social de la nación. Esta realidad emergente congregaba, como nunca antes lo hiciera otro espacio del acontecer peruano, al país, tanto en su totalidad, como en su heterogeneidad. Este aspecto entusiasmó a Arguedas por distintos motivos. En primer lugar, como un desafío personal. Marcado por su doble filiación, decidió entrometerse en la realidad que le era más ajena: el mundo de abajo. Siempre ligado al mundo indígena que lo cobijó en su niñez, penetró la realidad citadina e intentó escribirla. Así lo expresa en el Segundo Diario: «Sí, pues. Creo no conocer bien las ciudades y estoy escribiendo sobre una. Pero ¿qué ciudad? ¡Chimbote, Chimbote, Chimbote! [...] Esa es la ciudad que menos entiendo y más me entusiasma» $(97-98)^{2}$. En segundo lugar, la complejidad cultural y social de la ciudad de Chimbote implicó una apuesta mayor desde la perspectiva de la técnica

\footnotetext{
1 Extractos de sus cartas (desde 1966 y que tienen como foco la novela que nos convoca) han sido reunidos en el texto de Sybila Arredondo «El zorro de arriba y el zorro de abajo en la correspondencia de Arguedas», adjunto en la edición crítica de ALLCA XX/ Ediciones UNESCO, coordinada por Éve-Marie Fell. 2 Todas las citas de la novela corresponden a la edición de Sudamericana, 2003.
} 
narrativa, lo que se tradujo en este proyecto escritural polifónico de gran envergadura. El texto - el cual podemos definir como un ir y venir entre las distintas voces de los personajes y la del mismo Arguedas, quien relata su camino al suicidio en los llamados Diarios que se interponen en medio de la ficción - hace eco del complejo entramado social, étnico y cultural peruano. Hacerse cargo de esta nueva realidad implicaba reflexionar sobre cómo el proyecto modernizador, propugnado por la nación peruana de aquel entonces, enfrentaba la heterogeneidad cultural característica del Perú. Haciendo eco del discurso pronunciado por Arguedas al recibir el premio Inca Garcilaso de la Vega, la reflexión era en qué medida la modernización contribuía o no a abrir los «muros aislantes de las naciones» (12), sin que ello implicara la aculturación o aniquilación de la cultura indígena y la tradicional.

Centraremos nuestro análisis de El zorro de arriba y el zorro de abajo en esta última problemática: la tensión producida entre la incesante modernización y el espesor cultural tradicional de este país. Para ello nos focalizaremos en la representación de la ciudad de Chimbote que, de algún modo, ya hemos vislumbrado como una protagonista central de la novela. Desde esta perspectiva, las preguntas sobre las cuales girará nuestra reflexión son: qué tipo de ciudad nos presenta Arguedas en su obra y cómo su representación dialoga con una concepción determinada de modernidad y cultura. A modo de respuesta, plantearemos que Chimbote es una ciudad tensionada, donde culturas, modos de vida, ideologías, lenguas y etnias coexisten de modo desigual en un mismo espacio; tensión que produce heterogeneidad, pero no por ello armonía.

Las dos realidades en tensión que cohabitan en este mismo lugar citadino, guardan relación con las ideologías de la sociedad rural y la sociedad urbana. Tal como indica Romero en su artículo "Campo y ciudad: las tensiones entre dos ideologías", ambos espacios son dos realidades físicas disímiles, generadoras de sociedades, modos de vida e ideologías diferentes. En el caso de Chimbote, la realidad física corresponde a la de la urbe. Sin embargo, la ideología urbana y la ideología rural se entremezclan en este lugar, conformando un lugar diverso, pero siempre en tensión. En este contexto, procuraremos examinar algunos de los espacios que atraviesan los personajes de la novela de Arguedas, con el fin de comprender cómo se cruzan estas dos formas diferentes de interpretar la realidad. Aquello nos permitirá, finalmente, delimitar con claridad las bases sobre las cuales se asientan ambas ideologías y el porqué esta ciudad es, a fin de cuentas, representada como un espacio infernal, degradado y podrido.

\section{DESDE LA SIERRA A LA COSTA, DESDE LOS ANDES A CHIMBOTE: ÉXODO RURAL}

El título de la novela se enmarca dentro de «extirpador de idolatrías», una narración quechua recogida por Francisco de Ávila durante el período colonial. Arguedas la tradujo al castellano en 1966 con el título Dioses y hombres de Huarochirí. Sobre la importancia de este texto, señala en el prólogo: «es el único texto quechua popular conocido de los siglos XVI y XVII y el único que ofrece un cuadro completo, coherente, de la mitología, de los ritos y de la sociedad en una provincia del Perú antiguo» (9). ¿Qué retoma de esta visión mítica e indígena en su última novela? De acuerdo a la leyenda, en el cerro Latauzaco — donde dormía Huatyacuri, supuestamente hijo del dios Pariacaca— se reunieron 
dos zorros, cada uno proveniente de las dos regiones que dividían al mundo: la sierra y la costa, arriba y abajo. Tal como nos indica Vargas Llosa en La utopía arcaica, ambas regiones fueron centros dominantes de la historia peruana: la sierra antes de la llegada de los españoles y la costa luego de la conquista. José María Arguedas retoma esta división del mundo y la actualiza en su novela 2500 años después del encuentro mítico entre ambos zorros. Chimbote es el mundo de abajo y Los Andes el lugar desde donde provienen los miles de migrantes serranos, quienes, haciendo el movimiento inverso a lo narrado en el relato mítico, abandonan los cerros para bajar a la costa.

En las cartas del escritor peruano al antropólogo norteamericano John Murra recogen datos valiosos sobre sus investigaciones llevadas a cabo en Chimbote, específicamente, sobre el fenómeno de la migración. El 1 de febrero de 1967 le escribe: «He estado quince días en Chimbote. Es casi exactamente como Lima; tiene como 40 barriadas: el 70\% de la población es de origen andino; la masa de inmigrantes serranos es proporcionalmente mayor que la de Lima» (279). En la novela, Arguedas recoge este fenómeno migratorio y lo elabora literariamente desde sus desgarros y dislocaciones, pero también desde aquellos espacios urbanos que son intervenidos por un modo de vida rural y andino. Antes de interiorizarnos en este tipo de espacios, nos parece importante adentrarnos en el porqué de este éxodo rural.

El personaje que comprende a cabalidad este desplazamiento es Don Ángel Rincón Jaramillo, jefe de la planta de la fábrica de harina de pescado Nautilus Fishing, a quien críticos como Eugenia Brito y Martin Lienhard han identificado como la personificación del zorro de abajo. Miembro central del plan de Braschi (el gran explotador y proxeneta de la bahía, de quien todos hablan pero nadie ve), encarna el proyecto de nación peruano abierto a la industrialización del país y al mercado internacional, preferentemente a Estados Unidos. Si de acuerdo a García Canclini entendemos «la modernidad como etapa histórica, [y] la modernización como proceso social que trata de ir construyendo la modernidad» (165), diremos que el proyecto de nación peruano - encarnado en Don Ángel y en los demás secuaces de Braschi-implica una modernidad degradante que se instala a través de modernizaciones exclusivamente económicas, las cuales resultan siniestras para la mayoría de los habitantes de la ciudad.

Estas modernizaciones se traducen en la instalación de grandes industrias, fábricas y pesqueras, que explotan la bahía de Chimbote. En palabras de Zavala, pescador, sindicalista y gran meditador: «Esa es la gran «zorra» ahora, mar de Chimbote — dijo- Era un espejo, ahora es la puta más generosa, ‘zorra` que huele a podrido. Allí podían caber cómodamente, juntas, las escuadras del Japón y de los gringos, antes de la guerra. Los alcatraces volaban como señores dueños» (52). Además, esta modernización económica se traduce en el plano urbanístico de Chimbote en la instalación de alumbrado eléctrico, calles de cemento, sistemas de irrigación de agua potable, carreteras, ferrocarril y grandes hoteles; sin embargo, estas sólo involucran a ciertos sectores privilegiados de la sociedad: la clase dominante, conformada por los sectores ligados al poder empresarial, y la élite proletaria, instalada en el barrio El Trapecio.

Teniendo en mente esta ciudad moderna, los serranos bajan compulsivamente desde las alturas a la costa, soñando con esa modernización que promete trabajo, vivienda, luz, agua y quizás una lancha propia. En palabras de Esteban de la Cruz, minero serrano que escupe carbón esperando salvarse: «Parobamba, pueblito andino, nu'hay esperanza: chanchito, ovejita, chacrita chico; uno, dosito. [...] Entonces... en me pueblo; nu'hay esperanza diciendo. ¡Vamos, Jesusa, al Chimbote, puerto grandazo! Hey hablado. Mismo 
al siguiente mañana hemos bajado al carritera» (175). Pero la modernidad que instala Braschi — a través de las modernizaciones recientemente descritas- no pretende ser un proyecto expansivo que abarque a la sociedad de Chimbote en su totalidad. Muy por el contrario, él se ha preocupado de desarrollar toda una «mafia», mediante la cual atrae a los serranos a la ciudad, con el fin de que estos se conviertan en mano de obra y en derrochadores profesionales. De este modo se lo explica don Ángel a don Diego - el zorro de arriba- en su oficina de la planta:

La «mafia» antigua hizo correr la voz, como pólvora, de que en Chimbote se encontraban tierras buenas para hacer casas propias, gratis; que había trabajo en fábricas y en lanchas bolicheras, mercados, ladrilleras, tiendas, bares, restaurantes. Y así fue. La gente «homilde», como se llaman a sí mismos, bajó de la sierra a cascadas [...] A los pobrecitos serranos les haremos enseñar a nadar, a pescar. Les pagaremos unos cientos y hasta miles de soles y icajarete! como no saben tener tanta plata, también les haremos gastar en borracheras y después en putas y también en hacer sus casitas propias que tanto adoran estos pobrecitos (108-109).

El plan de Braschi, llevado a la práctica por la «mafia» y altos ejecutivos como don Ángel, funciona a la perfección. Multitudes de serranos, zambos, injertos y cholos arriban a Chimbote y se someten a las condiciones terribles de la ciudad con tal de permanecer en ella. La ansiada modernización no llega a la mayoría, sólo al «elegante» barrio obrero El Trapecio y a costa de profundos desgarros y desarraigos; no obstante, la migración se vuelve cada vez más explosiva. En palabras de don Ángel: «Más obreros largamos de las fábricas más llegan de la sierra. Y las barriadas crecen y crecen, y aparecen plazas de mercado en las barriadas con más moscas que comida» (104). La ciudad de Chimbote estalla y ocurre lo que José Luis Romero, al analizar la masificación de la ciudad latinoamericana, identifica como explosiones sociales dentro de la urbe sobrepoblada:

Y algunas estallaron. Las tensiones sociales se intensificaron, porque el crecimiento desmesurado de la población urbana originó un círculo vicioso: mientras más crecía la ciudad más expectativas creaba y, en consecuencia, más gente atraía porque parecía que podía absorberla; pero, en rigor, el número de quienes se incorporaban a la estructura urbana era siempre superior a lo que la estructura podía soportar. Era inevitable que la explosión urbana, nacida de una explosión sociodemográfica, desencadenara a su vez graves explosiones sociales en el seno de las ciudades (Latinoamérica: las ciudades y las ideas, 327).

De este modo, los sujetos migrantes - que en general son contemplados dentro del proyecto modernizador como mano de obra y jamás como beneficiarios del mismo- se instalan de forma problemática en la ciudad. Son excluidos del rostro afable de la ciudad moderna y confinados a la barriadas de los médanos o a orillas de las acequias. Desde este lugar, muchos de ellos entran en el engranaje devastador que el sector dominante ha creado para ellos. Basta pensar en personajes como Asto, el indio recién llegado a Chimbote, quien se jacta de su dinero ante la prostituta La Argentina en un castellano apenas digerido: «Tú, puta, blancota, huivona. Ahistá, carajo. Toma, carajo. Doscientos soles nada para mí. Puta, putaza. [...] Piscador juerte, machazo... Ochenta toniladas anchovita, yo» (48). Es el caso también de Orfa y Paula Melchora, prostitutas, o chuchumecas; la primera, madre de un niño forastero y la segunda, embarazada por Tinoco, ambas relegadas a las alturas de la barriada de San Pedro. Estos y otros casos tienen relación con aquellos migrantes que se han vuelto víctimas de una modernización despiadada. La otra opción parece aun peor: formar parte de la «mafia» y llegar a condiciones de 
degradación moral que, en ciertas ocasiones, abren las puertas de la ciudad moderna. Piénsese en Tinoco, el dueño del prostíbulo, quien llega a extremos tales como prostituir a su mujer Gerania y a su hermana Petronila. O Chaucato, patrón de la bolichera Sansón I e instalado en el barrio El Trapecio, compadre en su momento del temido Braschi.

Desde esta perspectiva, podríamos decir que, en distintas formas, los personajes son «urbanizados» por Chimbote. Tal como nos advierte Martin Lienhard en La voz y la huella, los fenómenos de interacción cultural ocurridos en Latinoamérica son marcadamente asimétricos, lo cual produce que los sectores marginados «salvo en los momentos de contraofensiva general, no tienen otro recurso sino el de reaccionar más o menos creativamente a la imposición de los valores o anti-valores hegemónicos» (135). De acuerdo a lo anterior, diremos que los personajes del mundo de arriba asentados en Chimbote, «ruralizan» la ciudad al intervenirla con sus modos y costumbres de la sierra al mismo tiempo que son «urbanizados». Evidentemente, la ideología andina o rural no se impone hegemónicamente en el puerto industrial; no obstante, tensiona el espacio y a la ideología urbana.

Desde este punto de vista, nos apropiamos de las ideas expuestas por Aníbal Quijano en «Urbanización y tendencias de cambio en la sociedad rural latinoamericana». En este artículo, el sociólogo peruano nos invita a dejar atrás aquel dualismo estructural que separa diametralmente lo urbano y lo rural. En esta línea, propone estudiar cómo las transformaciones en el plano urbano y rural están estrechamente ligadas: los cambios en la estructura tradicional del campo tienen relación con el proceso de urbanización, a la vez que las alteraciones a nivel urbano dejan entrever los cambios de la vida rural. Todo lo anterior y el palpable éxodo migratorio desde el campo a la ciudad, permite entrever cómo en la formación de las sociedades urbanas interviene un importante factor rural, a lo cual Quijano denomina «ruralización» (cfr. 46). De acuerdo a lo anterior, podríamos pensar que en la novela coexisten básicamente dos tipos de espacios. Por una parte, aquellos predominantemente rurales y andinos, intervenidos por el modo de vida urbano propio del mundo de abajo, en otras palabras, «urbanizados». Por otra, aquellos donde domina la ideología urbana y que en la mayoría de los casos son intervenidos por el modo de vida serrano, es decir, «ruralizados». Antes de introducirnos de manera detallada en la configuración de algunos de estos espacios, es importante destacar que el conjunto de todos estos lugares dan cuerpo a esta ciudad latinoamericana llamada Chimbote y a un modo particular de construir y pensar la modernidad.

\section{ESPACIOS RURALES Y ANDINOS «URBANIZADOS»}

Cuando hablamos de sociedad rural queremos decir, al mismo tiempo, sociedad indígena, específicamente, andina. Nos permitimos la extensión del término, ya que en América Latina las sociedades indígenas siempre han tenido, desde sus orígenes, una vinculación central con la tierra, lo cual da pie a un modo particular de entender la vida ligada a lo rural. A la vez, cuando usamos esta expresión queremos decir, además, sociedad tradicional que, de acuerdo a Leonidas Morales, entendemos como aquella identidad cultural que se ha visto erosionada y, en algunos casos, aniquilada por la instalación de la sociedad moderna: «la modernidad hispanoamericana ha multiplicado su tejido a expensas del de la sociedad tradicional» (15). Desde esta perspectiva, el crítico chileno inserta el 
proyecto literario de Arguedas dentro de la mejor literatura moderna hispanoamericana, cuyo propósito es «salvar el espíritu de la cultura étnica» (14).

En base a lo anterior, entenderemos por espacios rurales aquellos donde predomina una cultura y una ideología de raíz andina tradicional. Las barriadas que agrupan a los serranos migrantes son, sin duda, el espacio chimbotano más cercano a lo rural o, en otras palabras, a la cosmovisión andina de los pueblo altiplánicos. Este fenómeno tiene relación con el siguiente hecho: los sujetos migrantes se instalan en un nuevo espacio, la ciudad, pero traen consigo un modo de vida particular fuertemente arraigado. Entrevemos esta realidad en las palabras que Esteban de la Cruz le dice a su amigo el loco Moncada: "Cuando baja a la costa ya tamién recuerda so crianza, cerros, fiestas con borracherita, pito y caja, violín; llora silencio, ratito namás en el trabajo homilde, dispreciao ¡caracho!» (175). En El zorro de arriba y el zorro de abajo los personajes habitan dos tipos de barriadas, según los datos de don Ángel, 27 en total, reuniendo a cincuenta mil habitantes. Las primeras corresponden a aquellas ubicadas en los cerros o médanos desérticos de la ciudad y, las segundas, a aquellas instaladas a orillas del agua de acequia, llamadas por los serranos «aguadas».

Las barriadas de los cerros, entre las cuales destacan la barriada de San Pedro y la barriada La Esperanza, tan sólo por el lugar donde se ubican, dan cuenta de una fuerte filiación con el mundo indígena. De acuerdo a lo indicado por Juan van Kessel en «Individuo y religión en los Andes» — donde retoma los principios escudriñados por el filósofo José Estermann para definir la cosmología andina-, la relación que entabla el ser humano andino con la naturaleza es de afinidad y reciprocidad. A diferencia del pensamiento moderno, que sienta sus bases en una concepción antropocéntrica del mundo, la cosmovisión andina es agrocéntrica: «está centrada en la Tierra, pero una Tierra personificada y divinizada como la Madre universal e inmanente. De ello resulta una relación del hombre a su medio natural que es de diálogo respetuoso y de reciprocidad, y que considera las cosas como vivas y crías de la misma Madre Tierra» (16). Desde esta perspectiva, los cerros deben ser considerados como parte de esa naturaleza madre que marca a la mayoría de las tradiciones indígenas del continente; en el caso de la cultura andina, estos tienen una significación aún más especial. Primero, porque fue en los cerros donde se asentaron las diferentes culturas andinas (inca, aymara, quechua) y, por lo anterior, es el lugar desde el cual provienen los migrantes serranos. Segundo, porque de acuerdo a las narraciones de Dioses y hombres de Huarochirí, que Arguedas intenta integrar como material en su novela, los cerros son el lugar del mito y de las leyendas: en un cerro se reúnen los dos zorros y en las alturas de las montañas los dioses llevan a cabo sus hazañas. En este sentido, la instalación de las barriadas en los cerros no tiene que ver, meramente, con una estrategia urbanística que pretende relegar a los márgenes a los sectores populares. De alguna manera, los serranos bajan desde Los Andes hacia la costa, pero cuando se encuentran en ella suben a los cerros citadinos - extensión de las montañas del mundo de arriba en el mundo de abajo- buscando, quizás, aquella realidad dejada.

La primera escena donde aparece la barriada de San Pedro se encuentra en el primer capítulo de la novela:

Mientras, y flameadas por el viento, tres chuchumecas subían hacia la barriada de San Pedro, porunodeloscaminosqueseguíanlas piaras deburros delosaguateros. Eran putasdel «corral». No aceptaban pagar la costosa tarifa que los taxis de la ciudad pedían de noche para subir hasta la barriada del gran médano. Nunca se estaba seguro de que no se atascarían las ruedas (54). 
A través de esta breve descripción entrevemos cómo la ideología rural predomina en ese espacio. Los taxis de la ciudad, que debemos leer como signos de modernidad, no llegan a los cerros porque sus calles no han sido pavimentadas. El sendero ha sido marcado por los burros de los aguateros, lo cual devela que el sistema de irrigación de agua potable no llega a las barriadas; de ahí la supervivencia de este personaje tradicional. Los animales que acompañan al vendedor de agua nos remiten a la ganadería y, en consecuencia, a una visión agrocéntrica. Posteriormente, en esta misma escena, la prostituta Paula Melchora - embarazada por Tinoco y abatida por la realidad que vive-comienza a bailar un antiguo carnaval y canta. Vemos, entonces, cómo confluyen en el cerro elementos de la sociedad rural y andina: calles no pavimentadas, la figura del aguatero, animales y el carnaval bailado por Paula Melchora.

Otra escena ejemplar, también de la barriada de San Pedro: la casa del chanchero y dirigente Bazalar. La descripción de su vivienda nos habla de un lugar ganadero, donde los niños de Juana y Esmeralda (las dos mujeres del dirigente) conviven en un mismo espacio con diferentes animales: «Juana llevaba cargado en la espalda a uno de sus hijos, un niño como de dos años. Los otros niños, un poco mayores, jugaban con los patos y chanchitos que corrían en la pieza con la misma libertad y tolerancia que los niños. El mayor le rascaba la cabeza a un gallo que dormía en un palo bien ubicado en una esquina de la habitación» (241). Esta situación se vuelve aún más significativa cuando Esmeralda amamanta, con sus propios pechos, a la cría de un chancho que no puede ser alimentado por su madre. Tal como nos indica Vargas Llosa, debemos leer el gesto de esta mujer como una defensa de la naturaleza, acción que pocos personajes realizan durante la novela (cfr. 312).

Vemos, entonces, cómo las barriadas de los cerros mantienen un fuerte vínculo con la ideología rural. Danza, canto, sistema agrario y ganadero, mitos y naturaleza, empapan la realidad de los cerros, transformándolos en espacios predominantemente andinos, pero inmersos en la realidad del mundo de abajo, que ha propiciado la «urbanización» de estos espacios. En este caso, no debemos entender «urbanización» en el sentido literal de la palabra: sabemos que todas las barriadas carecen de calles de asfalto, iluminación eléctrica y sistema de irrigación de agua potable. Mediante este término, pretendemos dar cuenta de la intervención del mundo de abajo, con su ideología urbana, en estos espacios preferentemente rurales o andinos. La «urbanización» no se refiere al plan modernizador de la ciudad, sino más bien a aquella mentalidad urbana que han debido adquirir los personajes que habitan las barriadas y que coexiste con este vivir andino. El ejemplo más claro se da a nivel lingüístico: todos son, finalmente, hablantes de castellano ${ }^{3}$. Además, la gran mayoría trabaja en lo que la maquinaría de Braschi ha estipulado para ellos: pesca y prostitución. De ahí el baile de Paula Melchora, quien canta la melodía de un antiguo carnaval, pero con una letra que nos habla de la situación maldita que se vive

\footnotetext{
Esto se enmarca dentro del proceso de europeización lingüística de los sectores indios y mestizos, que Martín Lienhard distingue como uno de los dos movimientos que conforman la «aculturación» idiomática. El otro corresponde a la indigenización de los sectores criollos o de procedencia europea, que en la situación chimbotana representada en la novela es un fenómeno prácticamente inexistente (cfr. La voz y su huella, 137). El único caso que podría acercarse a este último movimiento es el de Maxwell. Este personaje norteamericano experimenta (luego de su estadía en el lago Titicaca) una suerte de indigenización a nivel cultural. No aprende el quechua, sino que el castellano; no obstante, interioriza gran parte del espesor cultural andino (toca charango, conoce los bailes tradicionales, tiene una relación amorosa con una mujer de Paratía en Puno), lo que lo conduce a dejar el Cuerpo de Paz y a vivir en la barriada La Esperanza junto a Cecilio Ramírez. En palabras de Maxwell al cura Cardozo: «Yo he dejado de ser yanki en un treinta o noventa por ciento» (259).
} 
en Chimbote; en su cantar, todo es «culebra», desde los cerros a Tinoco, desde los peces a la bandera peruana. Otro ejemplo de esta «urbanización» se trasluce en el modo en que Bazalar enfrenta la vida. Su vivienda se confunde con lo rural y está obsesionado con que las barriadas de Chimbote lleguen a ser como las de Lima, "que hasta carnet electoral partecolar, con escudo tienen y con ese actividad han conseguido ya alombrado eléctrico» (236). En medio de todos estos anhelos de modernización, Bazalar se vuelve consciente de que ya no es capaz de pensar en quechua.

Con respecto a las barriadas instaladas en las orillas de las acequias, diremos que estas se acercan a la ideología rural en tanto son expresión de la versión citadina de los totorales del altiplano. Mientras don Ángel y don Diego se dirigen al Gato Negro, pasan por una «aguada» sobre la cual el ejecutivo comenta lo siguiente:

Increíble, amigo Diego — dijo don Ángel—. Viven mejor, allí, es decir, mejor que una conjunción de patos y zancudos. Allí vive gente, cholos, indios; hay hasta tiendas, corralitos de chanchos, de cuyes y patos, entre la champa de falsa solidez de las orillas de esos fangales tan extraños en este desierto. Allí bailan, ciertos días, se emborrachan, levantan hasta banderas peruanas sin saber. [...] De la carretera hacia el mar y en los médanos, hay barriadas mejores, mucho mejores. Pero éstas de la aguada, oiga, no son tan tristes, no sé por qué porquería de razones. No son tan tristes (148).

A partir de la descripción del ejecutivo, percibimos que un fenómeno similar al de las barriadas de los cerros cobra vida en los totorales de las acequias: ambos lugares están fuertemente penetrados por la visión de mundo andina de sus habitantes. Es más, don Ángel intuye que esta realidad es menos triste que la de los médanos. Sin embargo, percepciones como las de Maxwell, el loco Moncada y Esteban de la Cruz (estos dos últimos habitantes del Totoral de La Calzada del barrio Bolívar), problematizan esta visión un tanto idílica de don Ángel.

En un tono absolutamente irónico, Moncada le habla a su entrañable amigo sobre el totoral que habitan:

Este lodazal-aguada es ahora un falso ano de la Corporación. La acequia que pasa delante de nuestras chozas, ¿qué es? Desagüe del lodazal; falsa vena, tripa de cagarrusa del lodazal. Y detrás de nuestras chozas está el anillo de totora que guarda el agua donde, ija, ja, ja!, algunas garzas de blanco inmaculado buscan gusanos. ¿Estamos en una lengüita de tierra barrosienta, compadre? Los catres de los vecinos que están más lejos del puente de la acequia, ¿no tienen sus patas metidas mismo en el barro como patas de asno, compadre? (164).

Si los totorales del altiplano se encuentran en las orillas de los lagos de las alturas, como en el caso del Titicaca; en Chimbote, los totorales están en las orillas de los desagües con excrementos. Si el prostíbulo es la «zorra» de la ciudad, el Totoral de La Calzada es el «ano» de la ciudad. El lenguaje escatológico utilizado por Moncada para describir el lugar donde vive, da cuenta de cómo este lugar, vinculado al mundo andino, ha sido degradado por la «urbanización». Esteban y Maxwell lo perciben del mismo modo. El primero se siente feliz ante los pájaros que revolotean sobre la barriada del totoral, pero estos carecen de la vitalidad que caracterizan a los de las alturas. La naturaleza, al igual que en las barriadas del cerro, está presente en el totoral, pero esta se muestra sin fuerza y degradada. Los pájaros vuelan de un modo diferente y el agua ha mutado en un fango oscuro: «A don Esteban le causaba aturdimiento alegre el aleteo y chillido de esos millares de pájaros que también había visto y oído en los lagos cristalinos de las grandes 
alturas; pero en la aguas frías la gaviota es rara, linda y airosa, y no forma bandadas que revuelven el cielo, como ésas que llegaban al fango del totoral cuyo fondo nadie ve ni conoce» (194).

En la barriada La Esperanza, donde vive Maxwell, se combinan ambos tipos de espacios: cerro y totoral. Ubicada en pleno desierto, luego de la llegada del acueducto de la irrigadora de Chimbote a las alturas de los médanos, surgieron ciénagas donde se instalaron «aguadas». El joven norteamericano las compara con las que conoció en el Titicaca, pero las figuras de los niños chimbotanos corriendo por el lugar le parecen desoladoras. Este lugar - propicio para el canto, la música y la danza- ha perdido su vigor para dar a luz a aquellas manifestaciones culturales de la vida andina:

Maxwell recordaba entonces la comunidad de Paratía y los totorales sin límites del lago Titicaca donde aprendió a tocar charango. La desolación de esas llanuras y aguas era diferente; los niños de La Esperanza, buscando nada en el fango y más, cuando el crepúsculo tropical marcaba nítidamente esas figuras, medio devorándolas, quemándolas, abultándolas, Maxwell podía tocar a veces las melodías y ritmos aymaras y quechuas que había aprendido, pero nunca jamás pudo cantar bien, y menos cuando lo pretendía, algo desesperado, frente a esos niños entre extraviados y curioseando en los fangales de la barriada (225).

En resumidas cuentas, son las barriadas de los cerros y los totorales los espacios chimbotanos donde más predomina la ideología rural, lo que, como ya hemos visto, no impide la intromisión de la ideología urbana. La «urbanización» no interviene a nivel de modernizaciones urbanas y aquello tiene relación con el plan macabro de Braschi, quien no pretende la instalación de un proyecto moderno expansivo, donde todos puedan ser beneficiarios de los bienes arrojados por las diferentes modernizaciones. Así, a lo largo de la novela, se va configurando un motivo particular en torno a la luz. En los espacios donde la ideología urbana es predominante, la luz es eléctrica; en los espacios donde la ideología rural sobresale, la luz es natural. Desde esta perspectiva, resulta interesante la descripción que hace don Ángel de la ciudad de Chimbote durante la noche. Parado junto a don Diego encima del trommel de la fábrica, su percepción es la siguiente:

Ya sabe; así es la cosa: Buenos Aires, después viene la oscuridad, varios kilómetros. En esa oscuridad están cinco barriadas, entre totorales, agua salada y viento; luego, nuevamente la oscuridad; después El Trapecio, el Casco Urbano, la Fundición y su barrio, los muelles y más oscuridad hacia los médanos y el mar. Digamos, treinta mil personas en los campos iluminados que vemos desde aquí; el resto, unas... digamos treinta barriadas, doscientos mil, viven en la basura y bajo la luz de las estrellas. Así tiene que ser (136).

De algún modo, la carencia de modernización urbana es la que ha posibilitado la permanencia de la ideología rural. El no tener agua potable los obliga a mantener figuras como el aguatero; las calles no pavimentadas posibilitan la ganadería y lo agrícola; ante la inexistencia de alumbrado eléctrico no hay más opción que la luz natural. En consecuencia, este tipo de lugares están fuertemente marcados por lo andino, aunque, claro está, en algunos casos su versión citadina es degradada. Es más, en ciertas ocasiones extremas estos espacios sucumben, definitivamente, ante la intervención de la ideología urbana; el ejemplo clave es el cementerio, del que los pobres deben sacar sus cruces, dejando el paso abierto al "cementerio moderno, norteamericano» (84), como lo llama Bazalar. No obstante, los serranos no se cansan de buscar el reencuentro con su filiación indígena, sobre todo en los cerros. Algunos la encuentran medianamente. Otros como 
Tinoco y Orfa — tal como se nos indica en el ¿Último Diario?, donde Arguedas relata el final que tendría su novela - suben a los cerros con las últimas esperanzas de mejorar su condición existencial, que, finalmente, ven frustradas:

No podré relatar, minuciosamente, la suerte final de Tinoco que, embrujado, con el pene tieso, intenta escalar el médano Cruz de Hueso, creyendo que así ha de sanar, y no puede avanzar ni un solo paso [...] Ni el suicidio de Orfa que se lanza desde la cumbre de El Dorado al mar, desengañada por todo y más, porque allí, en la cima, no encuentra a Tutaykire, trenzando oro ni ningún otro fantasma y sólo un blanqueado silencio, el del guano de isla (280).

\section{ESPACIOS URBANOS «RURALIZADOS»}

El empresario industrial don Ángel plantea el panorama del Perú a don Diego de la siguiente forma:

Siete huevos blancos contra tres rojos. Nosotros, la industria, U.S.A., el Gobierno peruano, la ignorancia de los cardozos sobre el pueblo peruano, somos las fuerzas blancas; Juan XXIII, el comunismo y la rabia lúcida o tuerta de una partecita del pueblo peruano contra U.S.A., la industria y el gobierno, son las fuerzas rojas. Fíjese; así es la cara del Perú, así, con sus tres rayitas rojas. [...] En resumen, amigo Diego, somos siete blancos contra tres rojos. Y uno de los rojos, el comunismo, está ahora como gusanera de muerto. Sé lo que digo. Y este mapa no va a variar en jamás de los jamases en contra del capital sino a favor. ¡Tiro seguro! Poquitos mandan en todo el universo, cielo y tierra, agua y mar (127-128).

Sus palabras dan cuenta de un proyecto de nación peruano que pretende abrirse aún más a la modernización, y con ello a la modernidad, pero que no es entendida de modo integral. Como ya hemos dicho, ésta sienta su base en una modernización exclusivamente económica, lo que implica la industrialización del país, de la mano de Estados Unidos. La modernización, desde un punto de vista social, cultural y político, queda atrás con tal de poder lucrar lo máximo posible con las riquezas naturales del Perú y de mantener en un reducido círculo las fuerzas conductoras y dominantes del país. De ahí que este proyecto moderno no pretenda ser expansivo y que los derechos sociales buscados por los trabajadores sean una gran molestia. Un claro ejemplo de esto último sería la huelga dirigida por Solano y las consecuencias negativas que ésta trajo para los trabajadores: con la manifestación consiguieron subir sus sueldos, pero luego la moneda fue devaluada intencionalmente y terminaron ganando menos que antes de las protestas. En palabras de don Ángel: «Ahora el pescador gana 30 por ciento menos que antes de la huelga. ¿Ya? No hay escape; en el Perú y el mundo mandamos unos cuantos» (118).

Este afán modernizador es el que ha logrado el despegue de Chimbote desde una aldea de pescadores a una gran ciudad industrial. El dinero que se ha obtenido de esta realidad se traduce, en el espacio de la ciudad, en ciertas modernizaciones de corte urbanístico, ubicadas en el Casco Urbano y otros sectores privilegiados. Desde esta perspectiva, deberemos entender que la ideología urbana que impera en Chimbote va de la mano de la modernización económica y de un selecto grupo dominante, conformado por los dueños de las empresas y sus familias. En este contexto, el espacio más emblemático de esta urbanización industrial son las decenas de fábricas y pesqueras instaladas en la ciudad. 
Cuando don Ángel le muestra a don Diego la fábrica de harina de pescado Nautilus Fishing, nos adentramos en una realidad absolutamente técnica, donde imperan maquinarias de toda índole: grandes ciclones que arrojan humo por sus chimeneas, un trommel usado para limpiar las anchovetas, una tolva que registra el peso de los pescados. Detrás de toda esta parafernalia maquinal, el ser humano desaparece cada vez más; objetivo perseguido por don Ángel para abaratar los costos y multiplicar las ganancias: "Quedan sólo un mecánico y su ayudante. Así es... Pero no hemos subido aquí al trommel a seguir discurseando sino para que usted conozca y vea lo que es una gran fábrica, cómo, ahora que es más grande, la manejan un cuarto de obreros menos que antes» (138).

Pero este espacio excesivamente urbano - donde la naturaleza sólo tiene cabida en los peces que han de ser triturados- es intervenido por la ideología rural que encarna don Diego. Repentinamente, ante el espectáculo de ocho máquinas, una alegría invade al zorro de arriba y comienza a bailar. Los obreros, quienes ya habían advertido la condición especial del visitante, se compenetran con este ambiente mágico: «una alegría así giraba en el cuerpo del visitante, giraba en silencio y por eso mismo, don Ángel, y los muchos obreros que estaban sentados allí, tomando caldo de anchoveta, apoyados en los muros de la galería, sintieron que la fuerza del mundo, tan centrada en la danza y en esas ocho máquinas, les alcanzaba, los hacía transparentes» (144). Así, la fábrica queda transmutada, por algunos instantes, en un espacio de condición andina, donde personajes míticos, el baile y la magia son la tónica.

Otro espacio enfáticamente urbano, donde interviene la ideología rural, es la estación del ferrocarril. La ideología urbana se encarna en el tren, maquinaria que desde el siglo XIX ha sido ensalzada como el emblema por excelencia de la modernidad. Sobre y en torno al riel de la estación del ferrocarril — que se dirige a Huallanca- se instala, diariamente, el mercado de La Línea. Tal como indica don Ângel, los mercados aparecen con la llegada de los serranos y se han instalado «sin regla ni orden, como el de La Línea, que usted habrá visto» (110). Este espacio marcado por la ideología urbana y su afán de progreso se ve desestabilizado por la irrupción caótica de los feriantes, verduleros, vendedores, niños, animales, tiendas y triciclos que pueblan el mercado:

La línea del ferrocarril partía en dos la calle y el mercado. A un lado quedaba el suelo donde se vendían animales vivos, granos, verduras, alfalfa; centenares de puestos. En la otra orilla, las barrancas de esteras, un hormiguero de puestos techados con pasadizo en sombra y una fila alegre de puestos "privilegiados» con mostradores que daban a la línea. La línea del ferrocarril era calle activa del mercado y sobre los rieles había puestos de vendedores de limones, flores, lechugas, jaulitas de cuyes, pequeños cajones de cartón llenos de pollos vivos. [...] A excremento, a frutas, a sudor, a yerbas medicinales, olía la parte techada del mercado. Alcatraces tristes sobrevolaban en el aire, pajareando sueltos, o miraban, con los picos colgantes, desde los techos bajos de las casas y ramadas. Alguna, alguna mujer les arrojaba tripas de pescado o desperdicios de chancho de mar. Si bajaban, los agarraban a patadas, los perseguían a trapazos, a palos; los perros se banqueteaban con ellos (71).

Los productos vendidos por los serranos también dan cuenta de la irrupción del mundo rural: todos se vinculan con lo ganadero y lo agrícola; sin embargo, la visión particular que los serranos tienen del trabajo relacionado con la naturaleza ha sido mediada 
por la lógica de la compra y venta, aspecto central de la ideología urbana capitalista ${ }^{4}$ En resumidas cuentas, ambos modos de vida se tensionan mutuamente en este espacio, aunque la ideología predominante es la de la urbe. La escena que representa este hecho con mayor significación es la de la locomotora, la que, al pasar por el riel, tritura a algunos cuyes y a un gallo. Luego de aquello, el loco Moncada se come al gallo muerto frente a diversas personas que se congregan a su alrededor y, detrás de su verborrea cargada de ironía, devela la verdad del puerto: «El gallo ha muerto, los cuyes han muerto; la locomotora mata con inocencia, amigos. Así los yankis de Talara Tumbes Limited, Cerro de Pasco Corporation. No; no son responsables. ¡Oh, ah, padre Cardozo, padre Tadeo, buenos amigos, vengan a resucitar a este gallo...!» (72). Posteriormente, en el ¿Último Diario?, Arguedas nos cuenta cómo la situación se radicalizaría en el final que pretendía escribir. La ideología urbana llegaría a las últimas consecuencias con tal de terminar con este mercado de La Línea intervenido por lo rural: tractores enviados por la municipalidad arrasarían con todo y, en aquel contexto, Moncada diría su último sermón.

Finalmente, otro espacio urbano amenazado por lo andino es el Hotel Chimú. Quien lleva a cabo esta acción es el loco Moncada, un zambo mulato quien, a pesar de no ser serrano, encarna y expresa el desgarro vivido por estos sujetos: lo que expresa en sus intervalos de locura es lo que nadie quiere escuchar. De este modo, el lugar que él interviene se «ruraliza» en tanto habla de aquel mundo indígena erosionado y de sus penurias. Moncada se dirige a este elegante hotel luego de haber estado con su gran amigo Esteban de la Cruz, lo cual no es un detalle menor para comprender el gesto del loco. En este espacio se realizaba un gran baile, el cual reunía al sector dominante chimbotano y peruano, ligado al quehacer empresarial. El invitado principal de la noche era el señor Lavalle, abogado de la Sociedad Nacional de Pesquería:

Cuando las parejas se movilizaban en el iluminadísimo hall, Moncada llegó al centro del salón, a trancadas muy largas, calculadamente majestuosas: «Caballeros, damas, autoridades terrestres — dijo—; voy a orinar carbón sobre el encerado de este piso. ¡No temáis! El agua-carbón saltará de'me ojo', de'me pecho, del 'mensajero mariposa que en el ramaje llores de retama... (168).

Evidentemente, el discurso de Moncada está atravesado por el dolor de Esteban de la Cruz; su sintaxis imita a ratos el castellano no bien interiorizado de su amigo y no por nada amenaza con ensuciar el piso con orina de carbón. De este modo, las penurias de los serranos se instalan por unos instantes en el espacio de entretenimiento de las clases dominantes. Al señor Lavalle le parece curioso, incluso entretenido, el sermón del loco Moncada: «A mí me entretuvo — dijo el abogado-. No he oído que en Lima existan predicadores así» (169). Don Ángel, que como ya hemos visto comprende a cabalidad el fenómeno que acaece en la ciudad industrial, le responde a Lavalle estableciendo una comparación entre la configuración urbana de Lima y la de Chimbote. En la capital peruana, el mundo de las barriadas no interviene en el de los sectores dominantes; por el contrario, en las calles de Chimbote ambos mundos coexisten y, debido a ello, es que

\footnotetext{
$4 \quad$ Desde el punto de vista andino, la utilización de los productos naturales se relaciona con una concepción particular del trabajo, el cual es entendido como un fin en sí mismo y no como un medio para lograr otros fines: «el trabajo es fin en sí, y es plenitud existencial, celebración de la vida y comunión con la divinidad: la Pachamama. [...] El trabajo es culto a la Tierra y la chacra es su templo. La mitología andina describe la visión en el más allá, como una existencia con trabajo en la chacra, sin pestes, ni daños climáticos, tranquilo y armonioso" (Van Kessel, 17).
} 
Moncada ha podido entrar a un baile del Hotel Chimú. A partir de estas reflexiones del ejecutivo, entendemos cómo la estructura urbana de Chimbote propicia el (des)encuentro entre la ideología urbana y la ideología rural. De ahí que podamos hablar de espacios urbanos matizados por lo rural y de lugares rurales intervenidos por lo urbano. La ciudad industrial se erige, entonces, como una urbe heterogénea y profundamente tensionada.

\section{LA UTOPÍA DE ARGUEDAS SEGÚN CORNEJO POLAR: UN PERÚ QUECHUA Y MODERNO}

Al igual que Antonio Cornejo Polar, creemos que la utopía de Arguedas era la construcción de un Perú como «nación quechua moderna, capaz de respetar sus orígenes y de realizarlos con plenitud y capaz también de asumir, asimilándola, la riqueza de la modernidad» (198). Esta idea se trasluce en el discurso dicho por el escritor peruano al recibir el premio Inca Garcilaso de la Vega, comúnmente conocido como «No soy un aculturado», donde se refiere a sí mismo como "un individuo quechua moderno» (11). ¿Qué debemos entender por esta expresión? Por su biografía sabemos que su vida estuvo marcada por una doble filiación: una de procedencia hispana, blanca, cristiana, moderna, del mundo de abajo, y otra de raíz indígena, quechua, mítica, vinculada a la naturaleza, del mundo de arriba. Arguedas, un individuo instalado entre ambas naciones o en el intersticio de las dos culturas, pretende romper los muros que han incomunicado a ambos mundos durante años, con el fin de que mutuamente se enriquezcan y extiendan: «El cerco podía y debía ser destruido; el caudal de las naciones se podía y debía unir» (12). En este sentido, entrevemos cómo la aspiración del escritor peruano es romper con una visión de cultura cercada e instalar otra donde predomine el intercambio y el enriquecimiento mutuo, lo que no implica la aculturación o el olvido pasivo de la cultura propia: «Yo no soy un aculturado; yo soy un peruano que orgullosamente, como un demonio feliz habla en cristiano y en indio, en español y en quechua» (12). Tal como indicó Cornejo Polar, la utopía personal de Arguedas deviene en una utopía para el Perú: una nación que conjugue el gran espesor cultural de los orígenes y lo mejor de la modernidad.

En base de lo anterior, podríamos afirmar que El zorro de arriba y el zorro de abajo viene a ser la contracara del proyecto utópico arguediano recientemente explicado: retrata un mundo no deseado. Como hemos podido divisar, la modernidad instalada en la ciudad industrial no contempla en su interior la permanencia libre y creativa del mundo quechua. En aquellos espacios donde la ideología rural aún permanece - ya sea de forma dominante o dominada- se manifiesta casi siempre de modo degradado, débil y confuso. Retomando las ideas de Morales, asistimos a los tejidos rotos de la sociedad tradicional. Esto último, porque la modernidad chimbotana sienta su base en una modernización de corte meramente económico, la que - transformada en un fin y no en un medio- es capaz de arrasar con todo con tal de mantener su dominio. Por el contrario, la instalación de la modernidad no implica la aniquilación de lo indígena en la utopía arguediana. Basada en una visión integral de la modernización, los aspectos políticos, sociales, culturales y económicos deben relacionarse de modo equilibrado para una saludable asimilación de lo moderno y una permanencia activa de los orígenes. 
Desde esta perspectiva, nos distanciamos de la postura de Vargas Llosa, quien propone que la utopía arguediana —o «la utopía arcaica» como él la denomina - sienta su base en un conservadurismo cultural enemigo de todo lo relativo a la modernidad. De acuerdo a lo anterior, Vargas Llosa lee El zorro de arriba y el zorro de abajo como un abierto rechazo a todo lo urbano, industrial, moderno y occidental: «Su ideal es arcádico, hostil al desarrollo industrial, antiurbano y pasadista» (307). Pensamos que esta lectura sobre la visión arguediana sienta su base en una concepción de cultura cercada, pues se plantea que la lucha de Arguedas consistió en revitalizar ese mundo indígena sumido en las cenizas, pero en su versión cerrada, purista y arcádica, es decir, sin contemplar el diálogo y la recreación con otras culturas.

Según nuestro punto de vista, lo que predomina en la última novela de Arguedas es una crítica a aquella modernidad aberrante instalada en Chimbote, no una hostilidad recalcitrante al proyecto moderno en sí. Tal como indica en «No soy un aculturado", lo que él pretende es establecer «un vínculo vivo, fuerte, capaz de universalizarse, de la gran nación cercada y la parte generosa, humana, de los opresores» (12). Chimbote - en tanto integra el mundo de arriba y el mundo de abajo en su interior- es el lugar donde las dos naciones rompen sus muros aislantes: ambas culturas se compenetran. Sin embargo, en la ciudad industrial los serranos se relacionan con la peor cara de los «opresores» y no con «la parte humana, generosa» que anhelaba Arguedas. Esta ciudad —que podría haber sido el lugar perfecto para la concreción de la utopía arguediana- hace eco de una modernidad degradante, incapaz de coexistir armónicamente con la cultura indígena. No obstante lo anterior, creemos que Arguedas no desdeña lo moderno, sino que menosprecia el rostro barbárico de la modernidad que se instala a costa de la cultura que siempre defendió. De ahí la imagen de Chimbote como la gran «zorra», la bahía prostituida por dinero y que huele a pudrición. O la configuración de la ciudad como un espacio infernal, que arde en la bahía en medio de las fábricas, la fundición y las plantas de harina de pescado.

Un aspecto importante de destacar es la profunda conciencia de la heterogeneidad cultural del Perú que subyace tras la utopía arguediana. Asumida esta condición, la nación quechua moderna se propone conciliar los diferentes rostros que conforman a este país, de modo simétrico y siempre creativo. Por el contrario, creemos que la vuelta a la arcadia indígena planteada por Vargas Llosa es, a final de cuentas, una respuesta atrincherada ante las naciones en conflicto; es volver a resguardarse en los muros aislantes que cercan a estos dos mundos mantienéndolos incomunicados. En El zorro de arriba y el zorro de abajo, Arguedas opta por enfrentarse, cara a cara, con esta realidad heterogénea. Lo realiza al situar su novela en Chimbote, la ciudad industrial del momento que convocó a zambos, negros, criollos, serranos, cholos, injertos y norteamericanos. Esta diversidad cultural, como ya hemos visto, se hace visible en el plano de la urbe a través de la enorme cantidad de espacios disímiles que la integran. Es, en pocas palabras, una ciudad que se tambalea entre una sociedad propiamente urbana y otra de corte rural. Desde esta perspectiva, resulta evidente que el Chimbote representado por Arguedas está lejos de las grandes ciudades modernas de Europa y Estados Unidos de aquel entonces. Sin embargo, resulta posible señalar que el Chimbote de la década de los 60 sobre el cual escribió Arguedas antes de morir sí es una urbe moderna, aunque, por cierto, a su manera. 
Tanto Néstor García Canclini como Bernardo Subercaseaux han reflexionado sobre la problemática de la modernidad latinoamericana. Siguiendo una línea similar, García Canclini propone no «medir nuestra modernidad con imágenes optimizadas de cómo sucedió ese proceso en los países centrales» (169). Por su parte, Subercaseaux nos invita a entenderla como «una modernidad distinta» y no "periférica o derivada» (Historias de las ideas, 27). De acuerdo con estos planteamientos, pensamos que la ciudad de Chimbote - que por extensión nos habla de ciertos procesos compartidos por Latinoamérica en general - da cuenta de la especificidad de nuestra modernidad. ¿Pero cuál sería esta particularidad? Al pensar Chimbote como una ciudad moderna, resulta innegable admitir que la modernidad de nuestro continente implica la coexistencia de modos de vida, culturas o ideologías disímiles. Si bien estamos de acuerdo con Morales cuando indica que la modernidad se instala a costa de la existencia de la sociedad tradicional, también creemos, de acuerdo a García Canclini, que ésta no desaparece del todo. Desde esta perspectiva, nos adscribimos a la idea de modernidad latinoamericana híbrida propuesta por el intelectual argentino, al mismo tiempo que, de acuerdo con la mirada crítica de Cornejo Polar frente a este concepto, pensamos que esta hibridez no debe entenderse como sinónimo de armonía ni de estancamiento infértil, sino más bien como una relación tensa, compleja y llena de fisuras ${ }^{5}$.

El ejemplo de esta modernidad heterogénea se da en Chimbote, donde la coexistencia tensa entre ideología urbana e ideología rural es patente. Pensamos, entonces, que la utopía de la «nación quechua moderna» de Arguedas se basa en este modo particular de entender la modernidad desde y en Latinoamérica, como un todo en tensión, heterogéneo, plural y diverso. Su utopía - anclada entre lo rural y lo urbano, lo quechua y lo moderno- recoge lo característico de nuestra modernidad latinoamericana; no obstante, el gran proyecto que anheló Arguedas iba más allá de la realidad heterogénea, híbrida y mestiza de Chimbote. La utopía arguediana no sólo implica la coexistencia de culturas, etnias e ideologías diferentes. Ante todo exigía que las relaciones entabladas entre las distintas culturas no estuvieran marcadas por ningún tipo de dominación, sino por un trato libre, respetuoso e integrador; aspecto que, evidentemente, no cobra vida en la ciudad de Chimbote, donde la modernidad heterogénea se vuelve aberrante y monstruosa ${ }^{6}$.

Dicho esto, creemos que en El zorro de arriba y el zorro de abajo Arguedas nos muestra la contrautopía de sus anhelos por medio de una ciudad podrida e infernal, invitándonos de esta forma a ser sujetos activos en el pensamiento y creación de una modernidad desde/en/para Latinoamérica. Una modernidad en la cual no basta la heterogeneidad o la diversidad, sino la capacidad de equilibrar la modernización con la convivencia libre, armónica y creativa de nuestra(s) cultura(s).

Estas ideas fueron expresadas en su artículo «Mestizaje e hibridez: los riegos de las metáforas».

Juan van Kessel indica que uno de los principios fundamentales de la cosmología andina es el de la complementariedad. De acuerdo a este, los sujetos andinos escasamente se inclinan hacia la disyunción exclusiva (o-o); más bien optan por una disyunción reconciliadora (y-y). Desde esta perspectiva, entendemos el rechazo profundo de Arguedas a cualquier tipo de dominación. Lo que mueve su utopía es la relación integradora de todas las partes $(\mathrm{y}-\mathrm{y})$ y no el ensalzamiento de algunas, a costa de la dominación y marginación de otras (o-o). 


\section{REFERENCIAS}

Arguedas, José María. El zorro de arriba y el zorro de abajo. 1971. Santiago: Sudamericana, 2003. Medio impreso.

Arredondo, Sybila. «El zorro de arriba y el zorro de abajo en la correspondencia de Arguedas». El zorro de arriba y el zorro de abajo. Edición crítica coordinada por ÉveMarie Fell. Madrid: ALLCA XX/ Ediciones Unesco, 1996. Medio impreso.

Ávila, Francisco de. Dioses y hombres del Huarochirí. Narración quechua recogida por Francisco de Ávila (¿1958?). J. M. Arguedas (trad.). Lima: Museo Nacional de Historia/ Instituto de Estudios Peruanos, 1966. Medio impreso.

Domingo, Andreu. «Prefacio: narrativas sobre población». Descenso literario a los infiernos demográficos.Distopía y población. Barcelona: Anagrama, 2008. Medio impreso.

Cornejo Polar, Antonio. «Un ensayo sobre 〈los zorros» de Arguedas». El zorro de arriba y el zorro de abajo. Edición crítica coordinada por Éve-Marie Fell. Madrid: ALLCA XX/ Ediciones Unesco, 1996. Medio impreso.

García Canclini, Néstor. «¿Modernismo sin modernización?». Revista de Sociología Mexicana 3 (1989): 163-189. Medio impreso.

Lienhard, Martin. La voz y su huella. La Habana: Editorial Casa de las Américas, 1990. Medio impreso.

Morales, Leonidas. Figuras literarias, rupturas culturales (modernidad e identidades culturales tradicionales). Santiago: Pehuén, 1993. Medio impreso.

Quijano, Aníbal. "Campo y ciudad en el contexto histórico latinoamericano». Desarrollo urbano y regional en América Latina. Problemas y políticas. Selección de Luis Unikel y Andrés Necochea. México: Fondo de Cultura Económica, 1976. Medio impreso.

Romero, José Luis. Latinoamérica: las ciudades y las ideas. 1976. Buenos Aires: Siglo XXI, 2005. Medio impreso.

. «Campo y ciudad: las tensiones entre dos ideologías». Cultura y sociedad en América Latina y el Caribe. París: Organización de las Naciones Unidas para la Educación, la Ciencia y la Cultura, 1981.

Subercaseaux, Bernardo. "Apropiación cultural». Historia de las ideas y de la cultura en Chile. Tomo III. Santiago: Universitaria, 2004. Medio impreso.

Van Kessel, Juan. «Individuo y religión en los Andes». Cuaderno de investigación en Cultura y Tecnología Andina 16 (2000): 3-33. Medio impreso.

Vargas Llosa, Mario. La utopía arcaica. José María Arguedas y las ficciones del indigenismo. México: Fondo de Cultura Económica, 1996. Medio impreso. 